\title{
Flood Hazard Mapping of Lower Indus Basin Using Multi-Criteria Analysis
}

\author{
Saba Zehra*, Sheeba Afsar \\ Department of Geography, University of Karachi, Karachi, Pakistan \\ Email: "ssabazehra@gmail.com
}

Received 11 March 2016; accepted 19 April 2016; published 22 April 2016

Copyright (C) 2016 by authors and Scientific Research Publishing Inc.

This work is licensed under the Creative Commons Attribution International License (CC BY). http://creativecommons.org/licenses/by/4.0/

(c) (i) Open Access

\begin{abstract}
Flooding has been one of the recurring occurred natural disasters that induce detrimental impacts on humans, property and environment. Frequent floods is a severe issue and a complex natural phenomenon in Pakistan with respect to population affected, environmental degradations, and socio-economic and property damages. The Super Flood, which hit Sindh in 2010, has turned out to be a wakeup call and has underlined the overwhelming challenge of natural calamities, as 2010 flood and the preceding flood in $\mathbf{2 0 1 1}$ caused a huge loss to life, property and land use. These floods resulted in disruption of power, telecommunication, and water utilities in many districts of Pakistan, including 22 districts of Sindh. These floods call for risk assessment and hazard mapping of Lower Indus Basin flowing in the Sindh Province as such areas were also inundated in 2010 flood, which were not flooded in the past in this manner. This primary focus of this paper is the use of Multi-criteria Evaluation (MCE) methods in integration with the Geographical Information System (GIS) for the analysis of areas prone to flood. This research demonstrated how GIS tools can be used to produce map of flood vulnerable areas using MCE techniques. Slope, Aspect, Curvature, Soil, and Distance from Drainage, Land use, Precipitation, Flow Direction, and Flow Accumulation are taken as the causative factors for flooding in Lower Indus Basin. Analytical Hierarchy Process-AHP was used for the calculation of weights of all these factors. Finally, a flood hazard Map of Lower Indus Basin was generated which delineates the flood prone areas in the Sindh province along Indus River Basin that could be inundated by potential flooding in future. It is aimed that flood hazard mapping and risk assessment using open source geographic information system can serve as a handy tool for the development of land-use strategies so as to decrease the impact from flooding.
\end{abstract}

\section{Keywords}

Flood Risk Assessment, Flood Predictive Modeling, Flood Hazard Map, Geographic Information System

*Corresponding author. 


\section{Introduction}

Flooding has been one of the recurring occurred natural disasters that inflict irrecoverable and detrimental impacts on humans, property and environment [1]. According to Domeneghetti et al., (2013), natural disasters are the major rationales of irreparable losses all over the world [2]. Hussain et al. (2011) emphasize that natural disasters irrespective of any type induce considerable damages to both properties and people [3]. Almost every year, mainly during the monsoon seasons, Pakistan encounters flood events which cause substantial losses to livelihood, properties, settlement, roadways, livestock and agricultural lands. Particularly, recent flooding in the years 2010 \& 2011 has caused considerable damages to Pakistan’s economy. Heavy flooding in the Indus, Kabul, and Swat Rivers resulted in the life loss of a large number of people along with considerable damage to settlements, infrastructure and agriculture along with river embankments. If an early warning system and appropriate mitigation plan would have been in place then these consequences could have been minimized or decreased. There is an utmost need for accurate flood modeling and risk assessment for the reduction and mitigation of disastrous impacts of floods. Various hydrological approaches have been proposed by researchers. These methods include traditional approaches like rainfall-runoff modeling techniques and contemporary approaches like data-driven techniques for generating the accurate flood models. Tehrany et al. (2014) put forward that substantial contributions have been made by geographic information system (GIS) and Remote sensing (RS) techniques in modeling and prediction of flooding events [4]. RS and GIS techniques enable rapid hydrological data collection and analysis for the sake of flood susceptibility and hazard mapping. The major objective of this study is to generate flood risk and vulnerability map of lower Indus Basin on the basis of land use, hydrological and geomorphological features. GIS is extensively utilized in this paper for the integration of several layers which depict rainfall, land-use, elevation and slope, and soil.

\section{Study Area}

Majority of the area of Sindh province falls in the Lower Indus basin that isgeographically located between latitudes from $66^{\circ} \mathrm{E}$ and longitudes $23^{\circ} \mathrm{N}$ and $23^{\circ} 31^{\prime} \mathrm{N}$ (see Figure 1). The lower Indus Basin is one of the tectonostratigraphic provinces of Pakistan [5]. The soil of lower Indus plain is very fertile and crops can be easily grown where ever there is a proper water supply; however, Thar Desert situated in the eastern part of basin is quite infertile because of water scarcity. A large network of canals irrigates northern and central part of Sindh. In the southern part of Sindh, Indus River gets closer to Arabian Sea forming a deltaic region. During the monsoon, a considerable part of lower Indus plain is flooded with water causing devastation. The reason for choosing the area is that in flooding events of the year 2010 \& 2011, one of the hardest hit areas was Sindh province as about 22 out of 23 districts of Sindh were affected by floods [6]. After receiving heavy rainfall in the monsoons, the Sindh province faced destructive flooding that's why it was picked out as an appropriate application site for flood susceptibility mapping and risk.

\section{Methodology}

The first step for the flood risk assessment and modeling is creation of a spatial database [7]. The database consists of various factors relevant to floods. GIS tools and techniques were used for the transformation of the considered factors into a grid spatial database. Digital Elevation Model (DEM) of 3 arc resolution of the study area was acquired through http://srtm.csi.cgiar.org/ [8]. The DEM of the study area was used for calculating the flow direction, flow accumulation, slope, hill shade and aspect of the area. Slope curvature was also calculated by means of the ESRI routine in Arc View. Land cover map of the study area was classified using a Landsat 8 image through unsupervised classification technique and base maps in Erdas Imagine 2014. The land cover map has been classified into different classes. The Meteorological data (precipitation) of stations in lower Indus Basin was collected from the Pakistan Meteorological Department. IDW technique was used for the interpolation of precipitation data for the whole study area over last twenty years. In order to have a general understanding and visual interpretation of the area, previous disaster history and satellite images (quick bird of resolution $0.6 \mathrm{~m}$ ) of the area were also acquired. The demographic data of the area was determined through secondary sources like Census Reports of different districts.

In the present study a combination of different data sets such as morphologic, topographic, satellite imagery, and census data (2001) obtained from concerned government agencies (Table 1) have been used to compute a 


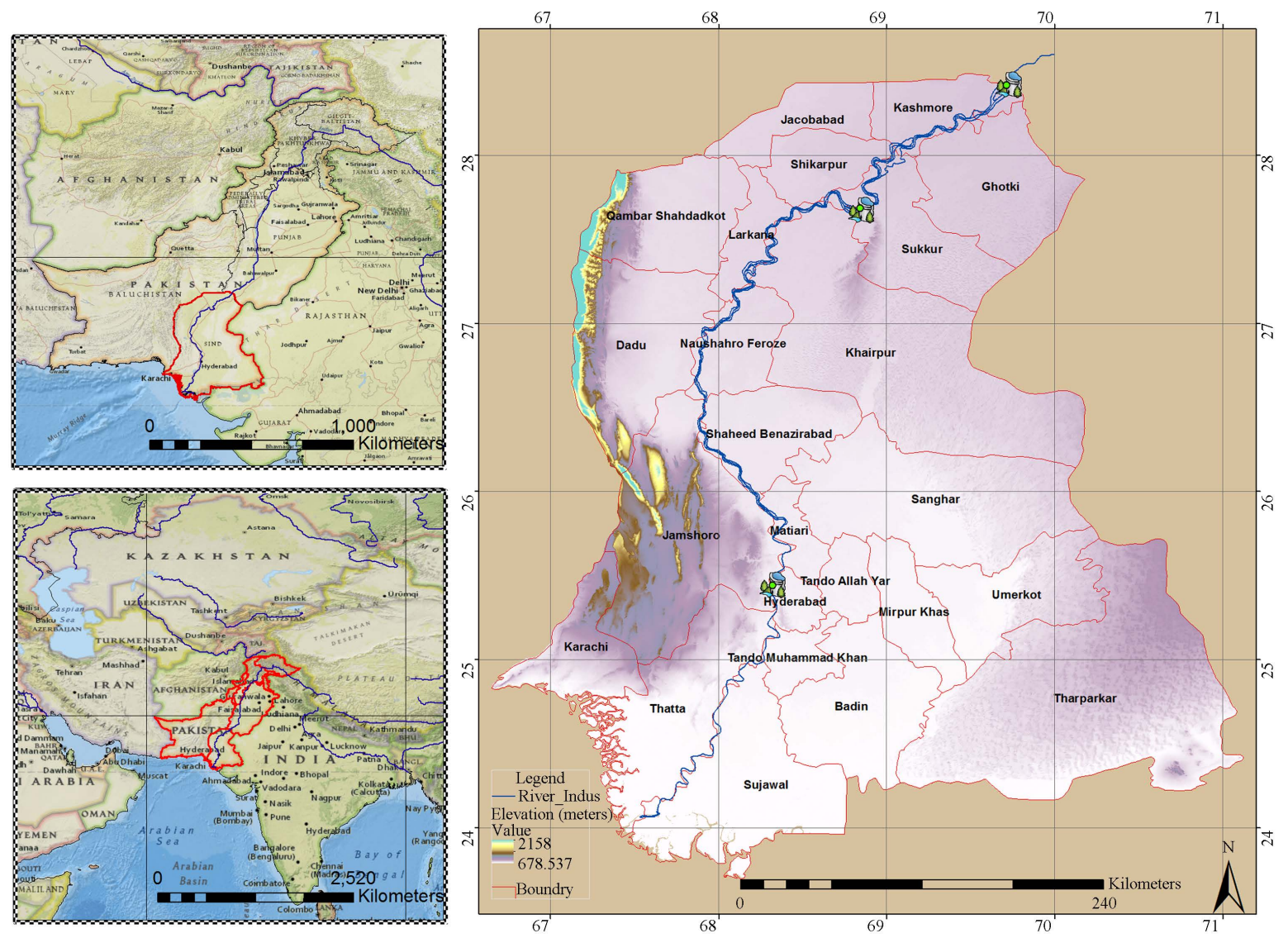

Figure 1. Map of study area.

Table 1. Spatial data used in the study.

Landsat 8 Image

Acquired Date: November, 2014

Digital Elevation Model

Slope and Drainage Density

Population Data

Rainfall (Precipitation) $\underline{\text { http://glcfapp.glcf.umd.edu }}$

http://srtm.csi.cgiar.org

DEM

Census Report

Pakistan Meteorological Department

composite index of flood risk based on multi-parametric analysis. The Multi Criteria Evaluation (MCE) approach through Rank Sum Method is used to identify the flood risk areas after assigned weights to each factor taken into consideration as per their sensitivity [9]. While conducted the present study following methodology schematically shown in Figure 2 is adopted. GIS application is fully used for reproducing, analyzing and integrated spatial data to prepare a flood risk map which not only defines the susceptibility of each settlement to inundation but also provides means for assessment of flood risk in terms of loss of life, crop land and property.

\section{Results \& Discussion}

Multi-criteria evaluation (MCE) methods have been applied in several studies. Since 80 per cent of data used by decision makers is related geographically [10], Geographical Information System (GIS) may provide more and better information about decision making situations. GIS allows the decision maker to identify a list meeting a predefined set of criteria with the overlay process [11]. In order to create flood risk maps ranking method is used and each factor is weighted according to the estimated significance for causing flooding. 


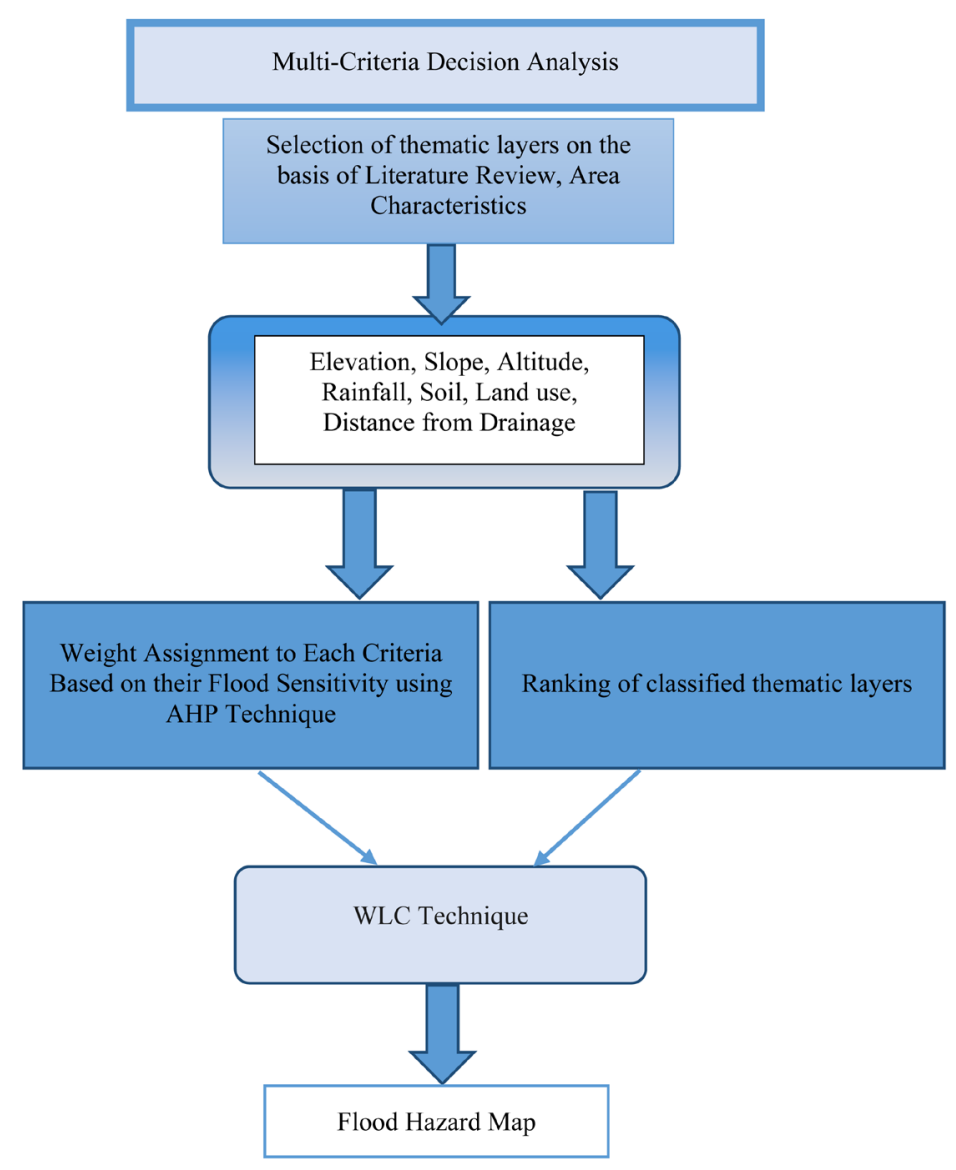

Figure 2. Methodological framework.

1) Elevation: The $90 \mathrm{~m}$ SRTM DEM was converted into elevation raster layers using the ArcGIS conversion tool. On the basis of the susceptibility to flooding, elevation has been classified into five classes. Areas with the lowest elevation are very much susceptible to flooding, thus ranked 1, which is less than $77 \mathrm{~m}$. Following the very high hazard class, there was a class high (77 - $232 \mathrm{~m}$ ) ranked 2, class moderate (232 - $534 \mathrm{~m}$ ) ranked 3, class low (534 - $1078 \mathrm{~m}$ ) ranked 4 and class very low ranked 5 (>1078 m) (Figure 3).

2) Soil: The soil map of Sindh was converted into raster and then reclassified into five classes on the basis of their flood generating capacity. The soil type having very high flood generating capacity was ranked as 1 , high ranked as class 2 , moderate ranked as class 3 , low ranked as class 4 and very low ranked as class 1 . Below are the soil map and reclassified map of soil (Figure 4).

3) Slope of the Lower Indus Basin: The $90 \mathrm{~m}$ SRTM DEM was processed in ArcGIS to determine the slope of the AOI. Youssef et al. (2011) put forward that slope is regarded as the surface indicator to identify flood susceptible areas as it plays an important role in finding out vertical percolation and surface runoff velocity and, hence have an impact on flood susceptibility [12]. The lower slope value implies a flatter terrain, whereas the higher the slope value will be, the steeper will be the terrain, and higher will be the runoff. There will be a higher probability in areas with the lesser slope degree, much water will be received in case of runoff. Slope has been classified into 5 classes on the basis of its susceptibility to flooding (Figure 5).

4) Rainfall (Precipitation): According to Musa et al. (2000), the availability of precipitation is regarded as a major source of recharge [13]. Adiat et al. (2012) [14] put forward that there is a significant impact of rainfall on the flood risk and the efficiency of MCDA. Monthly rainfall data of eight meteorological stations within the Sindh province for a period of 15 years (i.e., 1998-2012) were obtained from the Meteorological Department. Monthly data were then converted to annual mean. The average annual rainfall of selected stations of Sindh of the years 1998-2012 was interpolated using the IDW (inverse distance weighted) technique. The raster layer was classified into five classes. It is indicated from the acquired annual mean rainfall pattern that there is low rainfall 


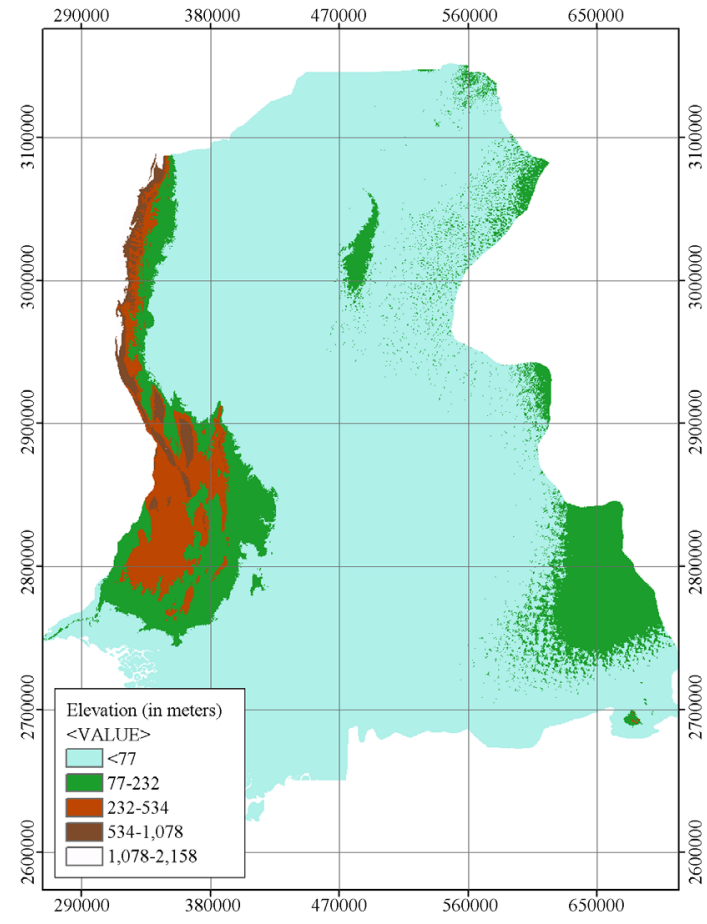

(a)

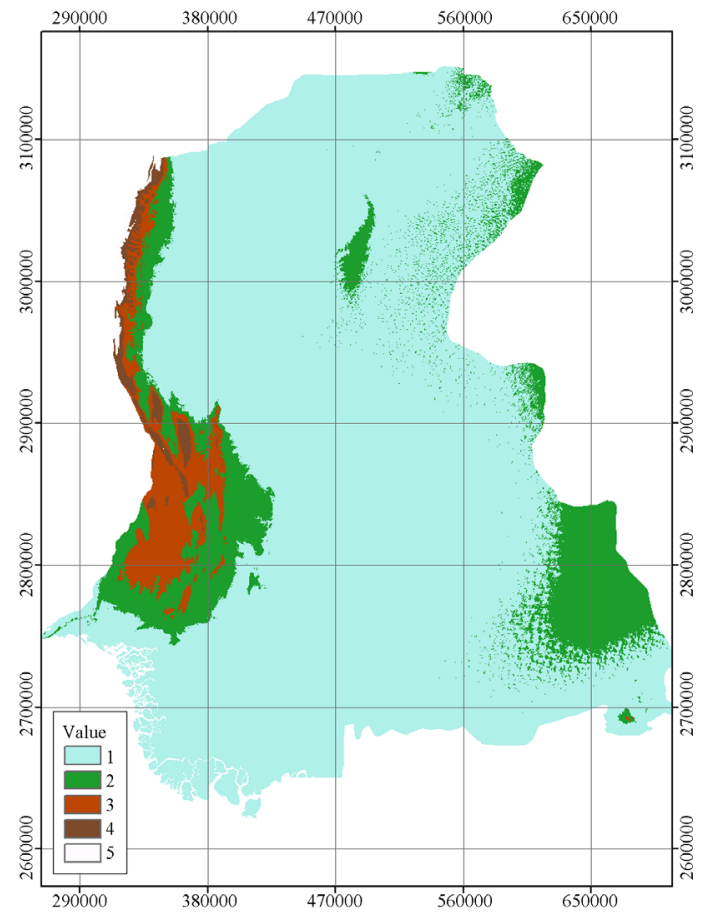

(b)

Figure 3. (a) \& (b): Elevation map \& reclassified map.

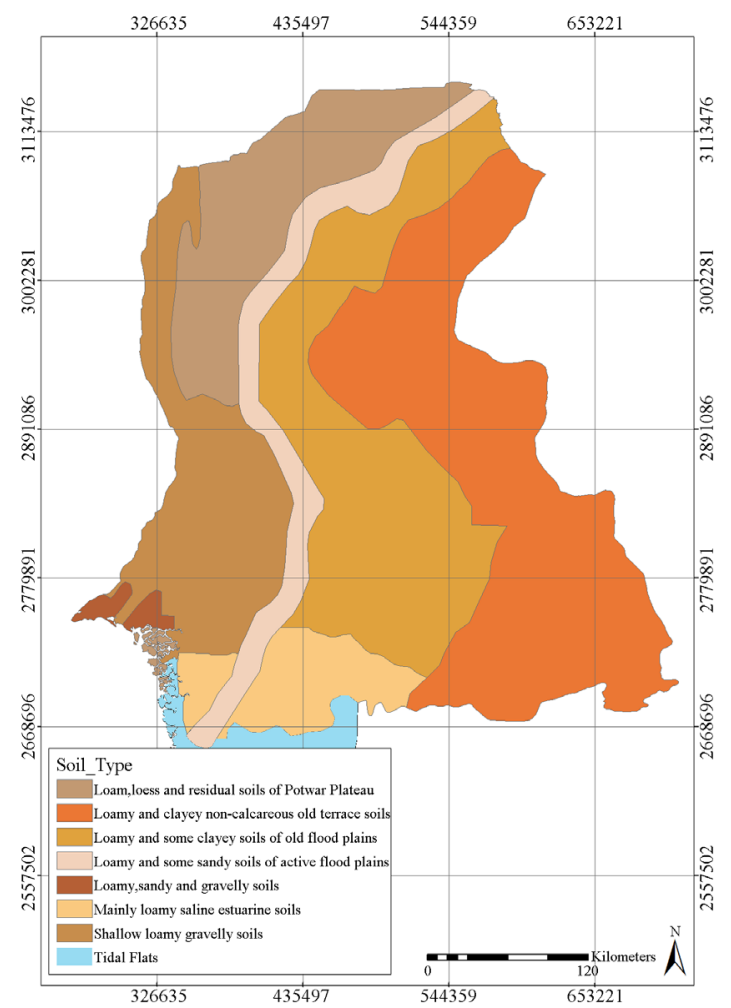

(a)

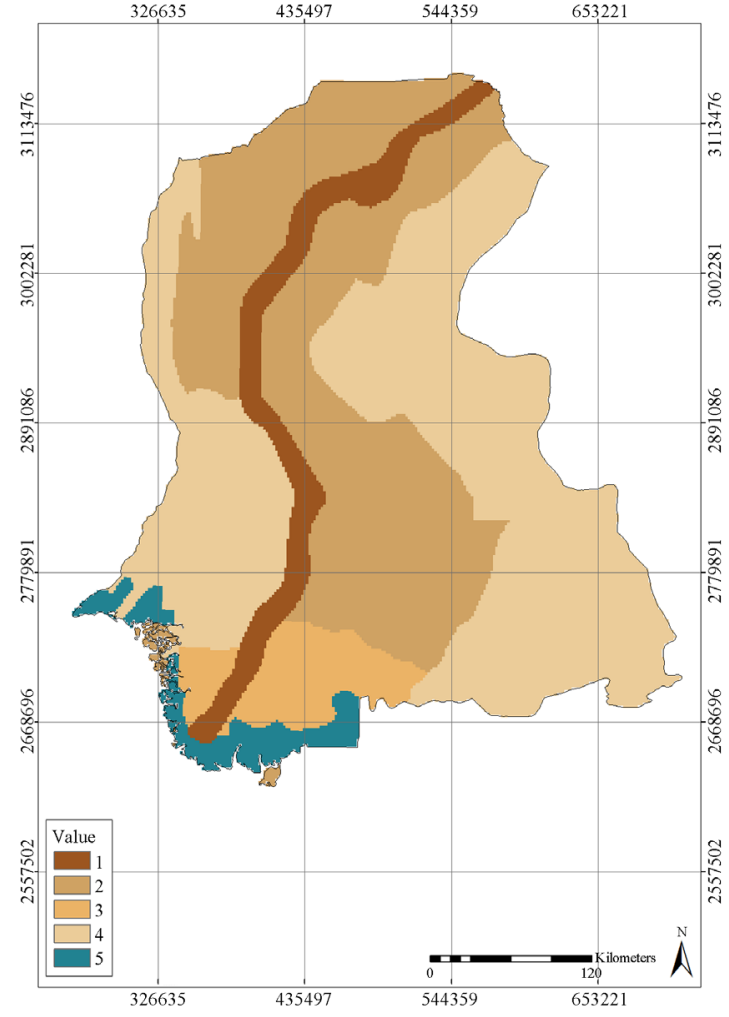

(b)

Figure 4. (a) \& (b): Soil map \& reclassified map. 


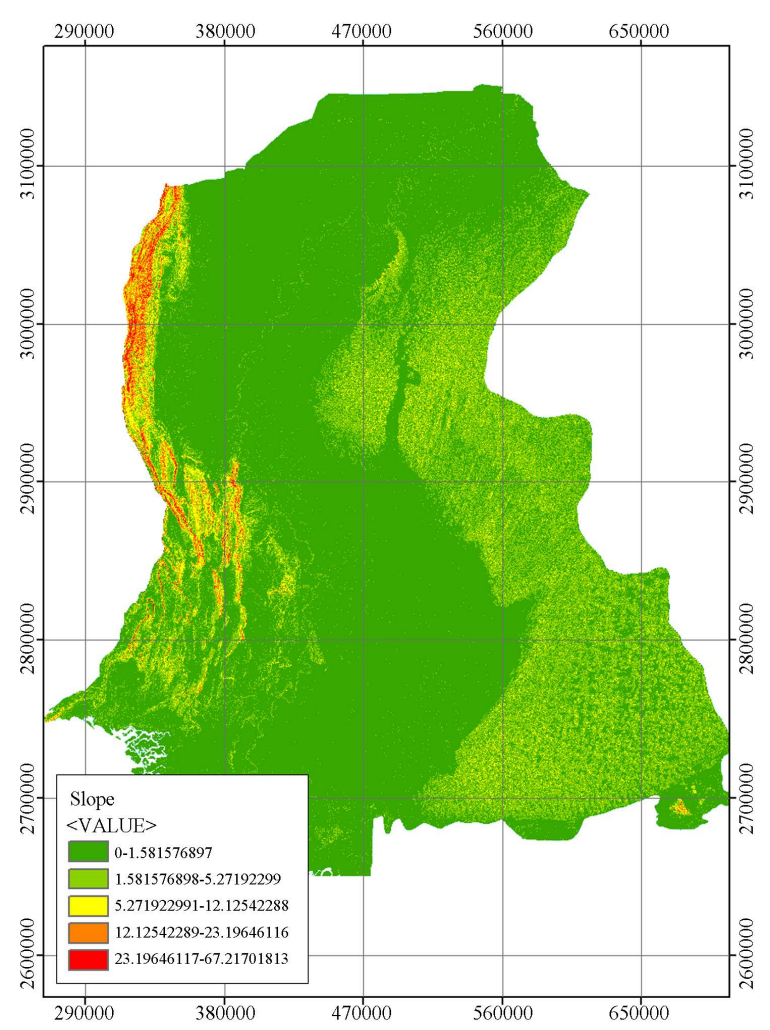

(a)

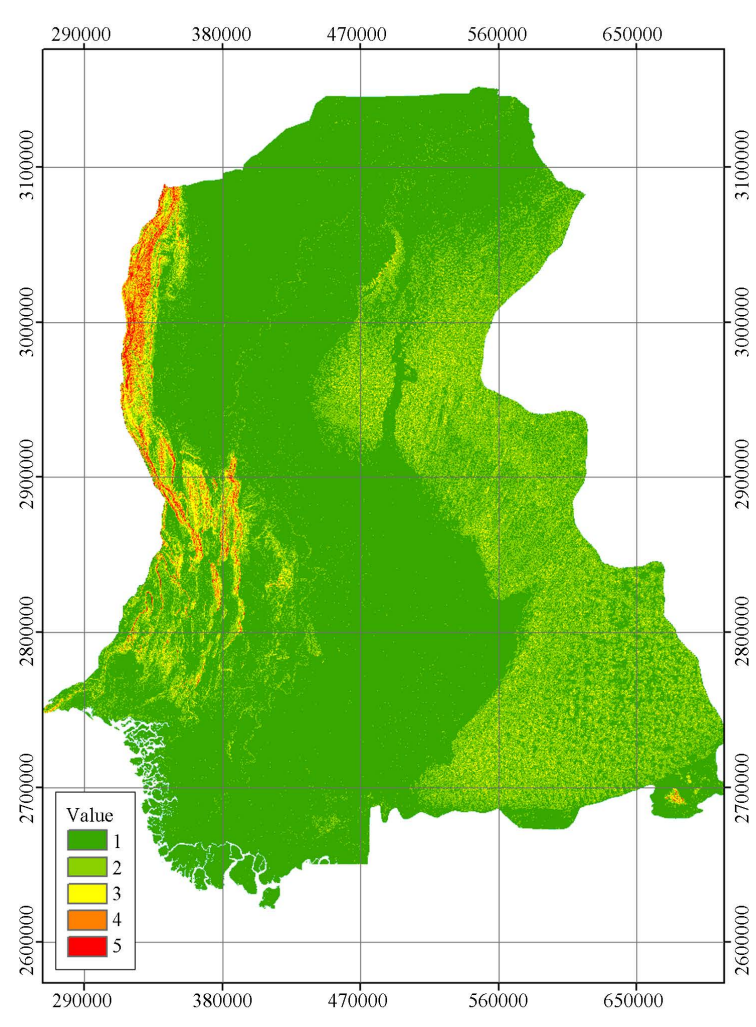

(b)

Figure 5. (a) \& (b): Slope map \& reclassified map.

in the upper Sindh while there is high precipitation in the southeast peripheries, and moderate rainfall in the western lowlands of the river basin. In the classification process, area with higher rainfall $(\mathrm{mm})$ is ranked 1 as it would be very highly affected by flood. Following the very highly susceptible to flooding class, there is a class high (191 - $223 \mathrm{~mm} /$ year), which is ranked as class 2, moderate (162 - $191 \mathrm{~mm} /$ year) ranked as class 3, low (136 $162 \mathrm{~mm} /$ year) ranked as class 4 and very low ranked as class 5 ( $<136 \mathrm{~mm} /$ year) (Figure 6).

5) Land Cover: The Landsat 8 image was obtained from http://glcf.umd.edu/data/landsat/. A composite was made and then the area was mosaicked, clipped area and processed in Erdas Imagine 2014. The unsupervised land use classification was run and the image was classified into different classes of Water, Forest, Agriculture, Barren Land, Mangroves, Swamp and Settlement. Based on the flood generating characteristics of the land use type, water as very high (class 1) cultivated land was assigned as high flooding (class 2), crop/vegetation land as high (class 4), open to closed vegetation/grass land as moderate (class 3), shrub land as low (class 2) and forest land as very low (class 1 ) as shown in Figure 7.

After the reclassification of all parameters, the pairwise comparison matrix of the flood hazard inducing parameters was performed in the AHP in ArcGIS to compute the weights. Finally a composite risk map of flood was prepared using the Raster Calculator using the below equation:

"Reclass_Slope" $\times 0.3366$ + "Reclass_Soil” $\times 0.3221$ + "Reclass_Elevation” $\times 0.2154$ + "Reclass_Rainfall” $\times$ 0.0743 + "Reclass_Landuse" $\times 0.0516$

It can be seen from the above map that the riverine areas are the most vulnerable to flood as floodwaters will hit the riverine areas along both banks of the Indus River. River Indus after receiving heavy precipitation and snowmelt can possibly cause floods in the northern (like Kashmore, Shikarpur, Larkana, Naushero Feroze, Shaheed Benazirabad) and southern parts (Jamshoro, Thatta, Hyderabad, Matiari, Tando Muhammad Khan) of the Sindh province. The flood risks can be mitigated through development of land-use zoning guidelines and their effective implementation for reducing the magnitude of flooding to a certain extent. People should not be restricted to build settlements in the flood plains through legislation (Figure 8). 


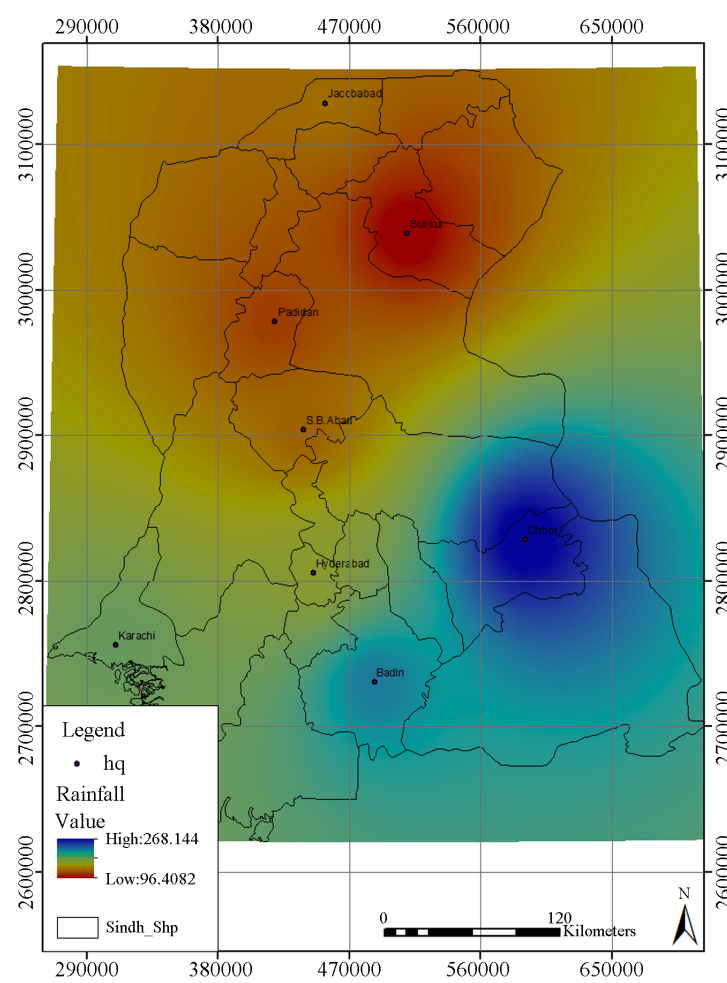

(a)

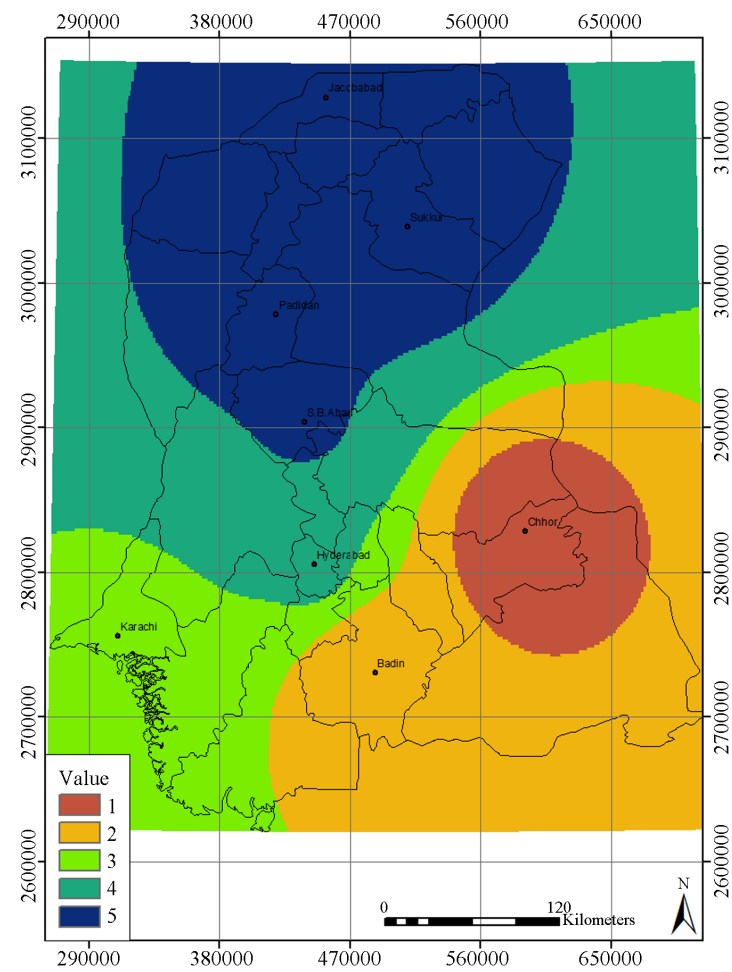

(b)

Figure 6. (a) \& (b): rainfall map \& reclassified map.

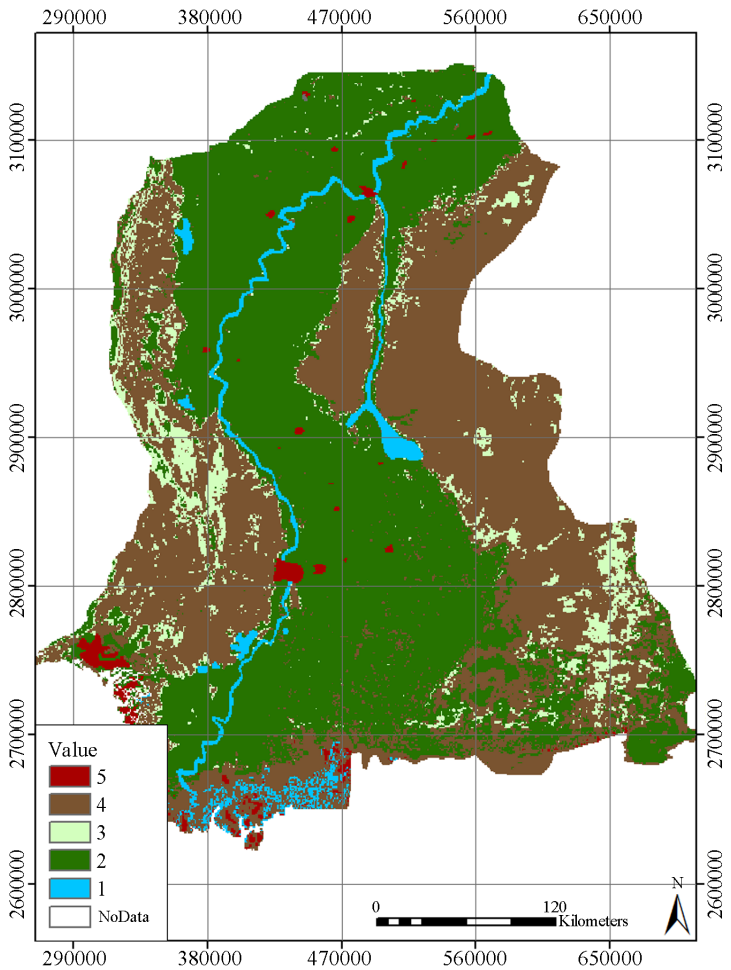

(a)

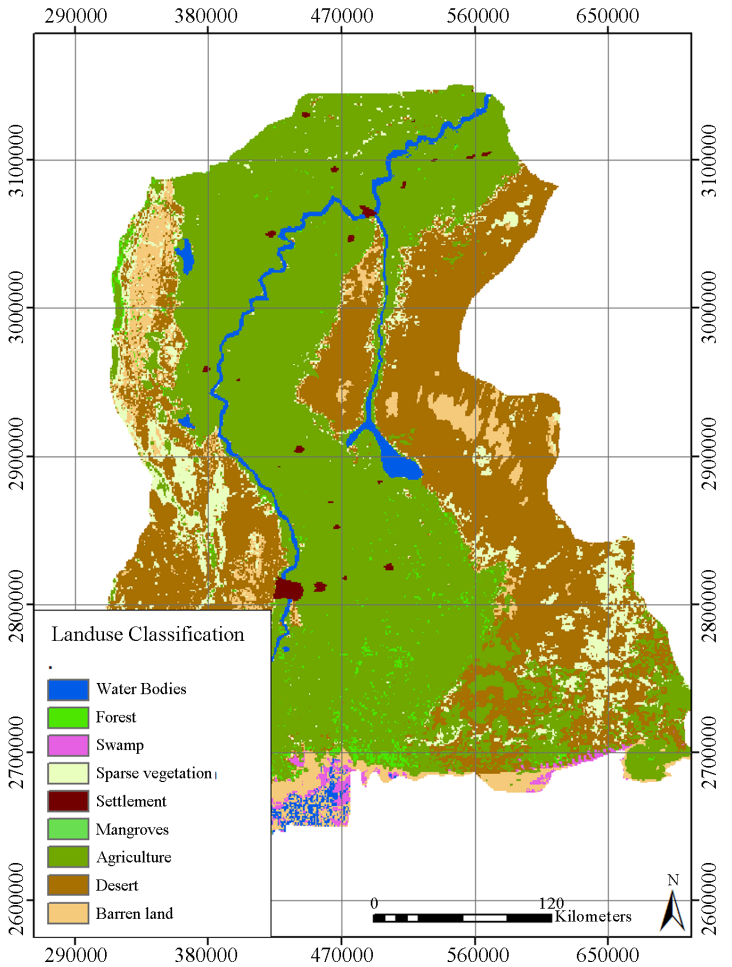

(b)

Figure 7. (a) \& (b): land use map \& reclassified map. 


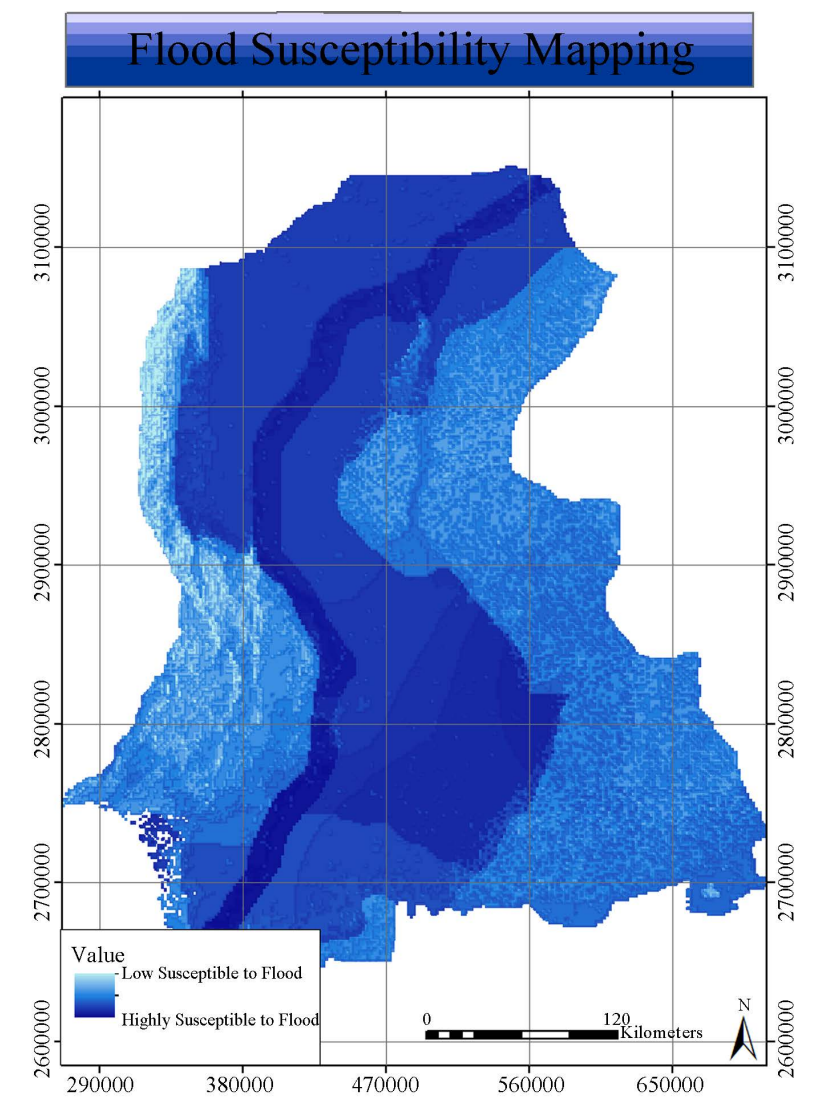

Figure 8. Final flood susceptibility map.

\section{Conclusion}

This paper presented a predictive model of flood of Sindh using AHP along with geographical information system. This paper initially constructed a spatial database of digital elevation model (DEM), geological and soil map, land cover map, topographical map and historical data of flood events for the evaluation of factors associated with flood vulnerability analysis. Then, this paper applied AHP technique to prepare flood vulnerability map. The flood hazard map delineated the flood prone areas that could be inundated by substantial flooding. To conclude, detailed information is needed for analysis of comprehensive flood risk analysis; such information could include hydrologic statistics, field conditions, \& characteristics of flood-defense structures in order to determine the severity \& extent of the flood impact of on the specific areas on the basis of probability-based result. In this study, with the methodology proposed, the integration of AHP and GIS can provide an initial assessment of the flood risk in the certain area. Moreover, GIS and AHP could provide the decision makers a more meaningful, interactive \& detailed flood risk assessment. It is anticipated that this study could be helpful for the local community \& flood managers to comprehend the factors causing flood plains inundation.

\section{References}

[1] Khan, B., Iqbal, M.J. and Yosufzai, M.A.K. (2011) Flood Risk Assessment of River Indus of Pakistan. Arabian Journal of Geosciences, 4, 115-122. http://dx.doi.org/10.1007/s12517-009-0110-9

[2] Domeneghetti, A., Vorogushyn, S., Castellarin, A., Merz, B. and Brath, A. (2013) Probabilistic Flood Hazard Mapping: Effects of Uncertain Boundary Conditions. Hydrology and Earth System Sciences, 17, 3127-3140. http://dx.doi.org/10.5194/hess-17-3127-2013

[3] Hussain, A., Weisaeth, L. and Heir, T. (2011) Psychiatric Disorders and Functional Impairment among Disaster Victims after Exposure to a Natural Disaster: A Population Based Study. Journal of Affective Disorders, 128, 135-141. http://dx.doi.org/10.1016/j.jad.2010.06.018

[4] Tehrany, M.S., Pradhan, B. and Jebur, M.N. (2014) Flood Susceptibility Mapping Using a Novel Ensemble Weights- 
of-Evidence and Support Vector Machine Models in GIS. Journal of Hydrology, 512, 332-343. http://dx.doi.org/10.1016/j.jhydrol.2014.03.008

[5] Khan, N., Konaté, A. and Zhu, P. (2013) Integrated Geophysical Study of the Lower Indus Platform Basin Area of Pakistan, International Journal of Geosciences, 4, 1242-1247. http://dx.doi.org/10.4236/ijg.2013.49118

[6] Memon, N. (2012) Malevolent Floods of Pakistan, Islamabad. Strengthening Participatory Organization, p. 8.

[7] Zerger, A. and Wealands, S. (2004) Beyond Modelling: Linking Models with GIS for Flood Risk Management. Natural Hazards, 33, 191-208. http://dx.doi.org/10.1023/B:NHAZ.0000037040.72866.92

[8] SRTM, C.C., 90m DEM Digital Elevation Database. http://srtm.csi.cgiar.org/

[9] Papaioannou, G., Vasiliades, L. and Loukas, A. (2015) Multi-Criteria Analysis Framework for Potential Flood Prone Areas Mapping. Water Resources Management, 29, 399-418. http://dx.doi.org/10.1007/s11269-014-0817-6

[10] Malczewski, J. (1999) GIS and Multicriteria Decision Analysis. John Wiley \& Sons, Hoboken.

[11] Heywood, I., Oliver, J. and Tomlinson, S. (1995) Building an Exploratory Multi-Criteria Modelling Environment for Spatial Decision Support. Innovations in GIS, 2, 127-136.

[12] Youssef, A.M., Pradhan, B. and Hassan, A.M. (2011) Flash Flood Risk Estimation along the St. Katherine Road, Southern Sinai, Egypt Using GIS Based Morphometry and Satellite Imagery. Environmental Earth Sciences, 62, 611623. http://dx.doi.org/10.1007/s12665-010-0551-1

[13] Musa, K.A., Akhir, J.M. and Abdullah, I. (2000) Groundwater Prediction Potential Zones in Langat Basin Using the Integration of Remote Sensing \& GIS. The 21st Asian Conference on Remote Sensing.

[14] Adiat, K.A.N., Nawawi, M.N.M. and Abdullah, K. (2012) Assessing the Accuracy of GIS-Based Elementary Multi Criteria Decision Analysis as a Spatial Prediction Tool—A Case of Predicting Potential Zones of Sustainable Groundwater Resources. Journal of Hydrology, 440-441, 75-89. http://dx.doi.org/10.1016/j.jhydrol.2012.03.028 